\title{
Gut focused behavioural treatment (biofeedback) for constipation and faecal incontinence in multiple sclerosis
}

Paul H Wiesel, Christine Norton, Amanda J Roy, Julie B Storrie, Jaqui Bowers, Michael A Kamm

\begin{abstract}
Objectives-To determine whether gut focused behavioural treatment (biofeedback) is a useful therapy in multiple sclerosis patients referred for constipation, incontinence, or a combination of these symptoms. Most patients with multiple sclerosis complain of constipation, faecal incontinence, or a combination of the two. Patients rate these bowel symptoms as having a major impact on their life. Until now the management of these problems has been empirical, with a lack of evaluated therapeutic regimes.
\end{abstract}

Methods-Thirteen patients (eight women, median age 38 years, median duration of multiple sclerosis 10 years) complaining of constipation, with or without faecal incontinence underwent a median of four sessions of behavioural treatment. Anorectal physiological tests were performed before therapy. Impairment and disability were rated with the Kurtzke score and the Cambridge multiple sclerosis basic score (CAMBS). Patients were contacted a median of 14 months after completion of treatment.

Results-A beneficial effect was attributed to biofeedback in five patients. Mild to moderate disability, quiescent and nonrelapsing disease, and absence of progression of multiple sclerosis over the year before biofeedback were predictive of symptom improvement. No physiological test predicted the response to therapy.

Conclusion-Biofeedback retraining is an effective treatment in some patients with multiple sclerosis complaining of constipation or faecal incontinence. A response is more likely in patients with limited disability and a non-progressive disease course.

(F Neurol Neurosurg Psychiatry 2000;69:240-243)

Keywords: multiple sclerosis; constipation; faecal incontinence; biofeedback Professor MA Kamm m.kamm@ic.ac.uk

Received 15 October 1999 and in final form

13 April 2000

Accepted 20 April 2000
Bowel dysfunction in patients with multiple sclerosis is common. Constipation or faecal incontinence occurs in $39 \%$ to $73 \%$ of such patients, depending on definitions and selection. $^{1-4}$ Both symptoms often coexist. ${ }^{5}$ Bowel management in patients with multiple sclerosis is empirical with a lack of evidence to support the recommendations commonly provided: high fibre diet, adequate fluid intake, physical exercise, regular bowel routine, manual evacuation of faeces, and use of enemas or laxatives. ${ }^{6}$

Behavioural treatment has found an important place in the management of patients with constipation and faecal incontinence. ${ }^{7}$ As pelvic floor incoordination has often been reported in multiple sclerosis, ${ }^{8}$ biofeedback may have a role for those patients with impaired evacuation. Moreover, the finding of an increased threshold of rectal sensation in incontinent patients with multiple sclerosis ${ }^{39}$ provides a focus for improving sensory awareness. To our knowledge no published study has reported the value of biofeedback in the management of bowel dysfunction in multiple sclerosis. The aim of this study was to assess the efficacy of biofeedback in patients with multiple sclerosis with either constipation or faecal incontinence. We also wished to determine which factors might predict the outcome of this therapy.

\section{Methods}

Thirteen consecutive patients with multiple sclerosis referred to our unit between May 1996 and May 1998, for bowel symptoms were entered into this study. All fulfilled widely accepted criteria for constipation. ${ }^{10}$ Nine patients also complained of faecal incontinence.

Intrinsic bowel pathology was excluded and endoanal ultrasonography was performed when appropriate. Anorectal physiological tests were routinely performed. Sphincter weakness and paradoxical contraction of the pelvic floor muscles during straining was evaluated. Impaired anorectal sensitivity to balloon distension and to an electrical stimulus were also assessed.

Using a standardised questionnaire data were prospectively collected about the duration and nature of bowel symptoms before treatment, immediately after completing treatment, and on follow up. Enquiries were also made 
Table 1 Patient characteristics, bowel symptoms, and benefit after biofeedback at follow up

\begin{tabular}{|c|c|c|c|c|c|c|c|c|c|}
\hline Sex & Age & $\begin{array}{l}\text { Bowel } \\
\text { symptoms }\end{array}$ & Disability & $D S S$ & $E D S S$ & $I S S-b o$ & $I S S-b l$ & $C A M B S$ & $\begin{array}{l}\text { Benefit at } \\
\text { follow up }\end{array}$ \\
\hline $\mathrm{F}$ & 26 & $\mathrm{CO}$ & Mild/Moderate & 2 & 4 & 2 & 0 & D1R1P1H1 & Marked \\
\hline $\mathrm{F}$ & 28 & $\mathrm{FI}$ and $\mathrm{CO}$ & Mild/Moderate & 3 & 4 & 3 & 3 & $\mathrm{D} 2 \mathrm{R} 2 \mathrm{P} 1 \mathrm{H} 3$ & Marked \\
\hline $\mathrm{F}$ & 38 & $\mathrm{CO}$ & Mild/Moderate & 2 & 6 & 3 & 0 & D2R2P1H2 & Moderate \\
\hline $\mathrm{F}$ & 50 & FI and $\mathrm{CO}$ & Mild/Moderate & 2 & 6 & 3 & 1 & D2R1P1H3 & Moderate \\
\hline $\mathrm{F}$ & 43 & FI and $\mathrm{CO}$ & Mild/Moderate & 5 & 4 & 4 & 4 & D2R1P1H4 & Moderate \\
\hline$M$ & 27 & $\mathrm{CO}$ and $\mathrm{FI}$ & Severe & 7 & 2 & 2 & 2 & D4R2P3H4 & Slight \\
\hline$M$ & 38 & $\mathrm{CO}$ and $\mathrm{FI}$ & Severe & 6 & 4 & 2 & 4 & D4R3P3H5 & Slight \\
\hline $\mathrm{F}$ & 49 & $\mathrm{CO}$ and $\mathrm{FI}$ & Severe & 6 & 4 & 3 & 0 & D3R2P1H3 & Slight \\
\hline$M$ & 35 & FI and $\mathrm{CO}$ & Severe & 6 & 6 & 4 & 4 & D3R3P2H4 & Slight \\
\hline $\mathrm{F}$ & 53 & $\mathrm{CO}$ and $\mathrm{FI}$ & Severe & 6 & 6 & 3 & 4 & D3R4P2H3 & None \\
\hline $\mathrm{F}$ & 56 & $\mathrm{CO}$ and $\mathrm{FI}$ & Severe & 6 & 2 & 3 & 2 & D4R3P3H5 & None \\
\hline M & 35 & $\mathrm{CO}$ & Severe & 7 & 2 & 2 & 0 & D4R3P2H4 & None \\
\hline M & 50 & $\mathrm{CO}$ & Severe & 8 & 6 & 3 & 3 & D4R3P3H5 & None \\
\hline
\end{tabular}

DSS=Disability status scale; EDSS=expanded disability status scale for bowel and bladder functions; ISS-bo= incapacity status scale for bowel; ISS-bl=incapacity status scale for bladder; CAMBS=Cambridge multiple sclerosis basic score.

Predominant symptom out of constipation (CO) and faecal incontinence (FI) is mentioned first. DSS has a range of 0 (normal neurological examination) to 9 (totally disabled, bed-restricted). EDSS section on bowel and bladder has a range of 0 (normal) to 6 (loss of bowel and bladder function). ISS rates bowel and bladder dysfunction separately, with a range of 0 (normal) to 4 (major incontinence or inability to maintain a stoma without assistance).

about the severity of abdominal pain or bloating. The use of bowel medication and the need to use pads were documented. At follow up patients were interviewed over the telephone by an investigator who had not been the therapist. Patients were asked whether they felt that biofeedback had helped them, and whether their constipation and incontinence had changed (no benefit, slight benefit, moderate benefit, or marked benefit).

Patients' multiple sclerosis status was assessed with the disability status scale (DSS), the expanded disability status scale for bowel and bladder (EDSS), and the incapacity status scale (ISS) for bowel and bladder. ${ }^{11}$ Assessment of disability and impairment, relapse, progression and handicap was made in accordance with the Cambridge multiple sclerosis basic score (CAMBS). ${ }^{12}$

PREDICTORS OF OUTCOME

To determine whether certain patient characteristics may predict a response to biofeedback, patients who thought that biofeedback had helped them (marked or moderate benefit) were compared with those who thought that they had not been helped (no or slight benefit). A comparison was made for the degree of disability and impairment, relapse in the year before treatment, and handicap. Anorectal physiological indices were also assessed for their prognostic value. Statistical analysis was performed by Fisher's test and $p<0.05$ was considered significant.

BIOFEEDBACK

A "package" of behavioural modification is often termed "biofeedback", although strictly speaking biofeedback refers to the conscious modification of body physiological processes having received a signal about body function. These techniques include attention to rectal and pelvic floor function, in addition to bowel retraining and use of medications. The treatment varies depending on whether constipation or faecal incontinence is the predominant symptom. We have previously published detailed descriptions of the biofeedback techniques used. ${ }^{13} 14$

\section{Results}

PATIENT CHARACTERISTICS

All patients were contacted and agreed to participate in the study (table 1). Median age was 38 years and median duration of multiple sclerosis symptoms 10 years (range 7-20 years). All had constipation, and nine had additional faecal incontinence. The median length of follow up from completing the course of biofeedback to the time of interview was 14 months (range 5-23 months).

Five patients were mildly to moderately disabled (DSS $\leqslant 5$ and CAMBS D1-D2). Eight patients were severely disabled and dependent on others for care (DSS $>5$ and CAMBS D3-D4).

Bowel dysfunction was marked. Ten patients had an EDSS of 4 or more, and nine had an ISS for bowel of 3 or more. ISS for bladder demonstrated the whole range of bladder dysfunction, with eight patients using an indwelling or external catheter. There was no correlation between the severity of bowel and bladder dysfunction, rated by EDSS or by ISS, and the severity of impairment and disability, rated by DSS or CAMBS.

\section{ANORECTAL PHYSIOLOGY STUDIES}

Most patients had abnormal physiological studies compared with our normal values. ${ }^{15}$ Maximum anal resting pressure (reflecting internal anal sphincter function) was normal for most patients (77\%), but most (62\%) had a weak voluntary squeeze pressure, including six out of the nine patients complaining of faecal incontinence. Nearly all patients (85\%) had impaired pelvic floor coordination on straining. Sensation to rectal distension was impaired in two patients and to an electrical stimulus in one of these patients. Both patients with impaired sensation were severely disabled.

\section{BIOFEEDBACK}

Each patient had one full course of biofeedback. Two to five sessions a patient were given over a period of 4 to 6 months. The number of sessions depended on whether the patient and therapist perceived that progress was being made. ${ }^{13}$ 
Table 2 Correlation of biofeedback benefit at follow up with disability, relapse, progression and handicap based on $C A M B S$

\begin{tabular}{llll}
\hline & & $\begin{array}{l}\text { Marked and } \\
\text { Moderate } \\
\text { benefit }(n=5)\end{array}$ & $\begin{array}{l}\text { Slight and No } \\
\text { benefit }(n=8)\end{array}$ \\
\hline \multirow{2}{*}{ Disability } & Mild or Moderate (D1 and D2) & $5^{\star}$ & 0 \\
& Severe (D3, D4, and D5) & 0 & 8 \\
Relapse & Quiescent or objectively unchanged (R1 and R2) & $5^{\star}$ & 2 \\
\multirow{5}{*}{ Progression } & Objectively worse than baseline (R3 and R4) & 0 & 6 \\
& None in past year (P1) & $5^{\star}$ & 1 \\
Handicap & Significant over past year (P2 and P3) & 0 & 7 \\
& Absent or Minor (H1, H2, and H3) & 4 & 2 \\
& Moderate or Major (H4 and H5) & 1 & 6 \\
\hline
\end{tabular}

Patients were scored in each of the four scales for their disability, relapse rate, progression, and handicap attributed to their multiple sclerosis according to CAMBS. Fisher's exact test, level of significance is ${ }^{\star} \mathrm{p}<0.05$. dysfunction. Biofeedback benefited patients with mild to moderate disability. Over a third considered themselves to have benefited in the medium term.

The assessment of patients with multiple sclerosis is difficult, as the natural history of the disease results in clinical deterioration and improvement over short periods of time. Although Kurtzke scales have gained international acceptance, we found that the imprecise terminology (for example, "retention of bowel", "measures to evacuate stool", "loss of bowel function", "occasional incontinence", "frequent soiling") rendered the application of the EDSS or the ISS unhelpful in both assessing patients' dysfunction, and in assessing response to biofeedback. Kurtzke himself has criticised the EDSS since the separation between scores is narrow especially at the middle grades. ${ }^{17}$ The CAMBS has been shown to be a reliable outcome measure in patients with multiple sclerosis. ${ }^{18}$ We found that using the four component structures of the scoring system delivered a great deal of information in a simple way and that the assessment of disability, relapse, and progression all correlated with the response to biofeedback.

Constipation may be associated with either prolonged colonic transit time, ${ }^{8}$ or with pelvic floor dysfunction. ${ }^{819}{ }^{20}$ Altered colonic compliance in patients with advanced multiple sclerosis $^{21}$ may be a factor. Medications commonly prescribed to patients with multiple sclerosis, such as muscle relaxants or anticholinergic drugs, are also known to cause constipation. Finally, psychological factors or behavioural problems may also affect toileting.

Impaired faecal continence can be related to bowel or sphincter disturbance. The bowel can generate very high pressures during contraction, resulting in urgency and incontinence. If the anal sphincter is weak, the pressure in the anal canal is not maintained so that patients leak stool without being aware of it. Any or all of these mechanisms can occur. Factors linked with multiple sclerosis, such as fatigue, general muscle weakness, spasticity, poor mobility, and difficult access to the toilet can also contribute to incontinence.

Anorectal pathophysiological findings were consistent with previous studies. ${ }^{381922}$ The reduced squeeze pressure (reflecting external anal sphincter dysfunction) may be related to multiple sclerosis in the same way that function of any striated muscle can be impaired. Whether the pelvic floor incoordination shown in some patients with multiple sclerosis ${ }^{20} 23$ should be regarded as a behavioural phenomenon, as in non-neurologically impaired patients, or as related to the multiple sclerosis, as in the multiple sclerosis related dyssynergia of striated urethral muscle, ${ }^{24}$ is as yet unknown. Impaired anorectal sensation was an infrequent finding in our patients, as reported by others. ${ }^{8}$ Impaired rectal or anal sensitivity to an electrical stimulus suggests that multiple sclerosis may be involved in the pathogenesis of the incontinence in some patients, as these tests are usually normal in non-neurological causes of incontinence. Due to the small size of the 
group no physiological test was predictive of the outcome.

Biofeedback aimed to condition patients to be more sensitive to a stimulus distending the rectum and to heighten the voluntary striated muscle sphincter response. Behavioural modification and improving pelvic floor function is the main goal. Bowel management in patients with multiple sclerosis involves counselling, health education, and biofeedback among other behavioural techniques. The main finding in this study was that patients with mild and moderate multiple sclerosis have a reversible component to their bowel dysfunction.

PHW is supported by a grant from the Swiss Multiple Sclerosis Society.

1 Miller H, Simpson CA, Yeates WK. Bladder dysfunction in multiple sclerosis. BMF 1965;i:1265-9.

2 Hinds JP, Wald A. Colonic and anorectal dysfunction associated with multiple sclerosis. Am f Gastroenterol 1989;84 587-95.

3 Nordenbo AM, Andersen JR, Andersen JT. Disturbances of anorectal function in multiple sclerosis. $\mathcal{F}$ Neurol 1996;243 445-51.

4 Bakke A, Myhr KM, Gronning M, et al. Bladder, bowel and sexual dysfunction in patients with multiple sclerosis: a cohort study. Scand $\mathcal{F}$ Urol Nephrol Suppl 1996;179:61-6.

5 Hinds JP, Eidelman BH, Wald A. Prevalence of bowel dysfunction in multiple sclerosis. A population survey. Gastysfunction in multiple sclerosis.

6 Corazziari E, Badiali D. Management of lower gastrointestinal tract dysfunction. Semin Neurol 1996;16:289-96. 7 Rao SS, Enck P, Loening-Baucke V. Biofeedback therapy for defecation disorders. Dig Dis 1997;15(suppl 1):78-92.

8 Weber J, Grise P, Roquebert M, et al. Radiopaque markers transit and anorectal manometry in 16 patients with multiple sclerosis and urinary bladder dysfunction. Dis Colon Rectum 1987;30:95-100.
9 Caruana BJ, Wald A, Hinds JP, et al. Anorectal sensory and motor function in neurogenic fecal incontinence. Comparion between multiple sclerosis Gastroenterology 1991;100:465-70.

10 Thompson WG, Drossman DA, Heaton KW, et al. Functional bowel disorders and functional abdominal pain. Gastroenterol Int 1992;5:75-91.

11 IFMS. International Federation of Multiple Sclerosis Socieies. Symposium on a minimal record of disability for multiple sclerosis. Acta Neurol Scand Suppl 1984;101:1-217.

12 Mumford CJ, Compston A. Problems with rating scales for multiple sclerosis: a novel approach-the CAMBS score. $\mathcal{F}$ Neurol 1993;240:209-15.

13 Chiotakakou-Faliakou E, Kamm MA, Roy AJ, et al. Biofeedback provides long-term benefit for patients with intractable, slow and normal transit constipation. Gut 1998;42:517-21.

14 Norton C, Kamm MA. Outcome of biofeedback for faecal incontinence. Br 7 Surg 1999;86:1159-63.

15 Jameson JS, Chia YW, Kamm MA, et al. Effect of age, sex and parity on anorectal function. Br f Surg 1994;81:1689and 92 .

16 Klarskov P, Heely E, Nyholdt I, et al. Biofeedback treatment of bladder dysfunction in multiple sclerosis. A randomized trial. Scand $\mathcal{F}$ Urol Nephrol Suppl 1994;157:61-5.

17 Kurtzke JF. The disability status scale for multiple sclerosis: apologia pro DSS sua. Neurology 1989;39:291-302.

8 Sharrack B, Hughes RA, Soudain S, et al. The psychometric roperties of clinical rating scales used in multiple sclerosis. Brain 1999;122:141-59.

19 Mathers SE, Ingram DA, Swash M. Electrophysiology of motor pathways for sphincter control in multiple sclerosis. 7 Neurol Neurosurg Psychiatry 1990;53:955-60.

20 Chia YW, Gill KP, Jameson JS, et al. Paradoxical puborectalis contraction is a feature of constipation in patients with multiple sclerosis. F Neurol Neurosurg Psychiatry 1996;60: $31-5$.

21 Haldeman S, Glick M, Bhatia NN, et al. Colonometry, cystometry, and evoked potentials in multiple sclerosis. Arch Neurol 1982;39:698-701.

22 Waldron DJ, Horgan PG, Patel FR, et al. Multiple sclerosis: assessment of colonic and anorectal function in the presence of faecal incontinence. Int f Colorectal Dis 1993;8: $220-4$.

23 Jameson JS, Rogers J, Chia YW, et al. Pelvic floor function in multiple sclerosis. Gut 1994;35:388-90.

24 Betts CD, D'Mellow MT, Fowler CJ. Urinary symptoms and the neurological features of bladder dysfunction in multiple sclerosis. F Neurol Neurosurg Psychiatry 1993;56: $245-50$. 